\title{
Modeling soil organic carbon dynamics and its driving factors in global main cereal cropping systems
}

Guocheng Wang ${ }^{1 *}$, Wen Zhang ${ }^{1 *}$, Wenjuan Sun $^{2}$, Tingting Li $^{1}$, Pengfei Han ${ }^{1}$

${ }^{1}$ State Key Laboratory of Atmospheric Boundary Layer Physics and Atmospheric Chemistry, Institute of Atmospheric Physics,

5 Chinese Academy of Sciences, Beijing, China

${ }^{2}$ State Key Laboratory of Vegetation and Environmental Change, Institute of Botany, Chinese Academy of Sciences, Beijing 100093, China

Correspondence to: Guocheng Wang (wanggc@mail.iap.ac.cn) 


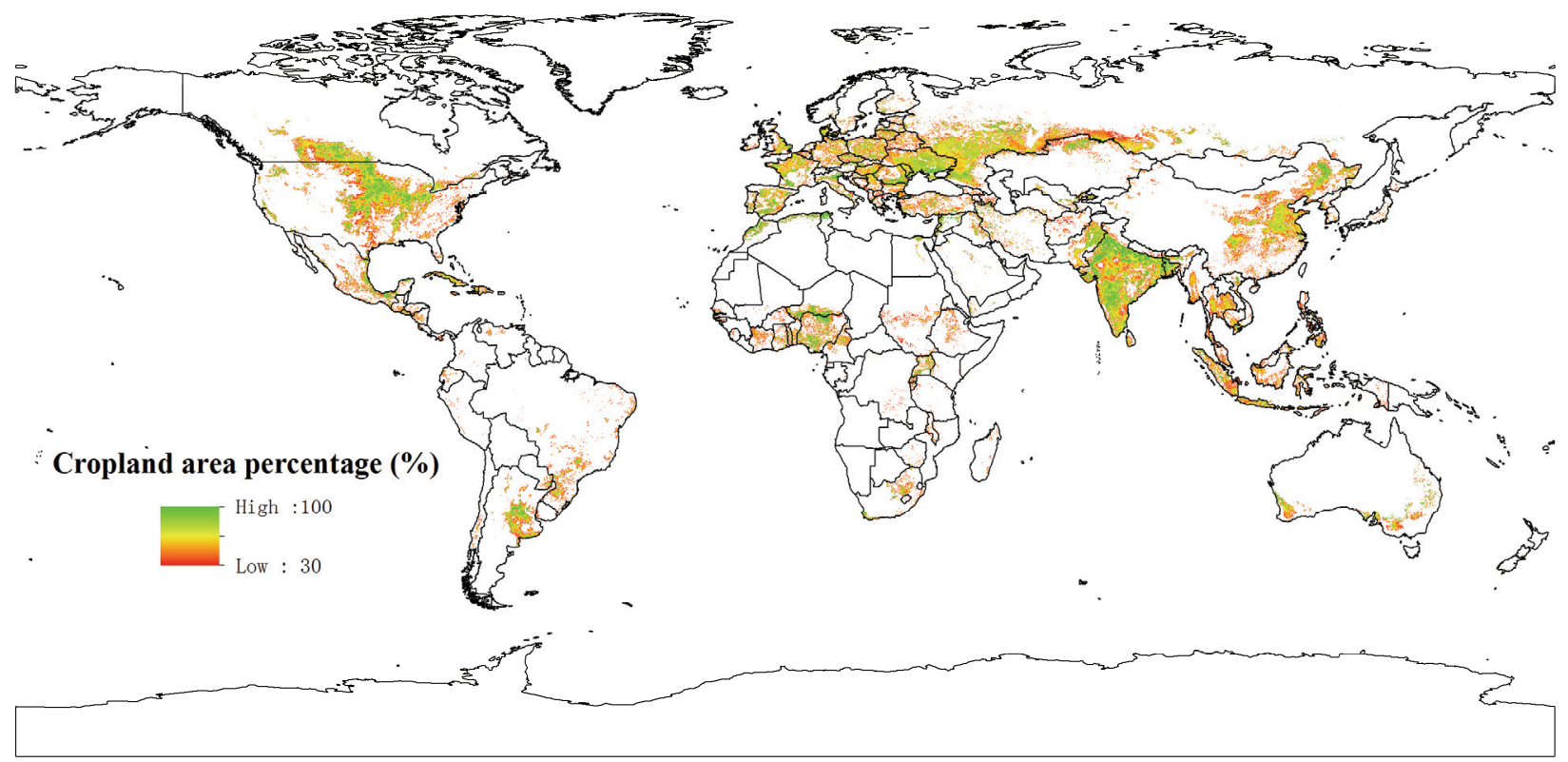

Figure S1. Spatial distribution of the main cereal-growing areas across the world. 


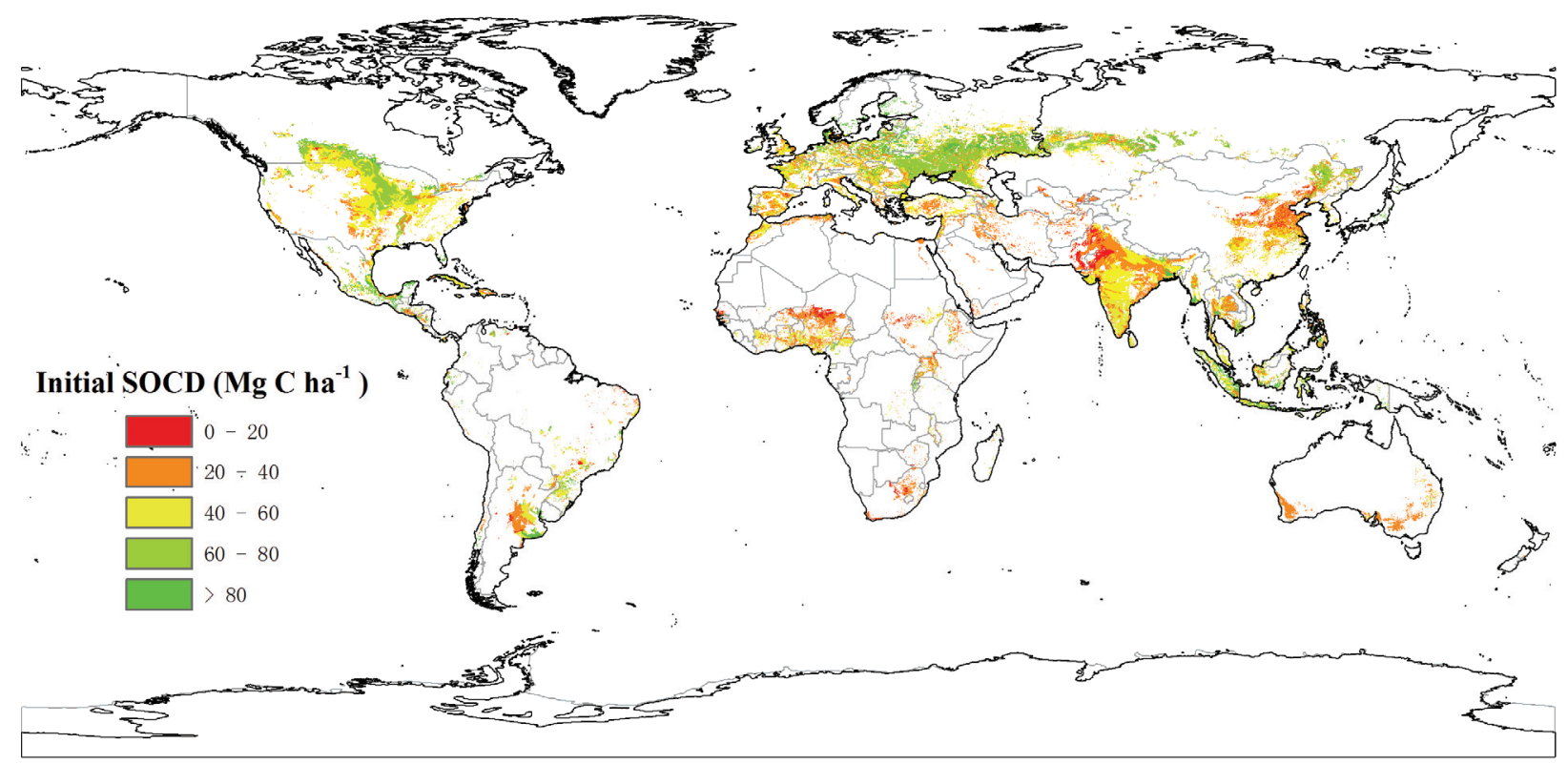

Figure S2. Spatial distribution of the initial soil organic carbon density across the global main cereal-growing areas. 

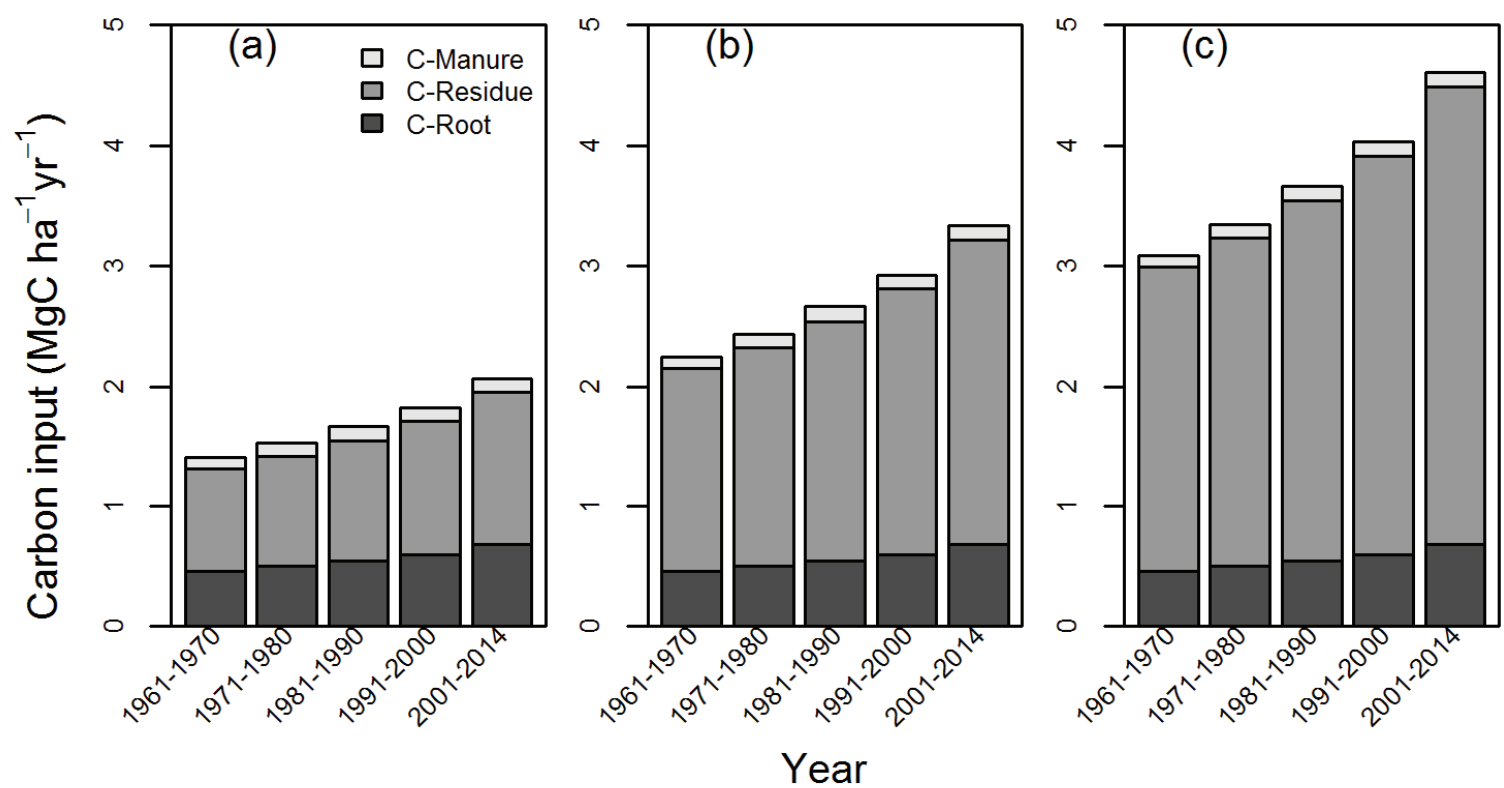

Figure S3. Temporal variations of carbon inputs in the global main cereal cropping regions under different above-ground crop residue retention rates of 30\% (a), 60\% (b) and 90\% (c). 

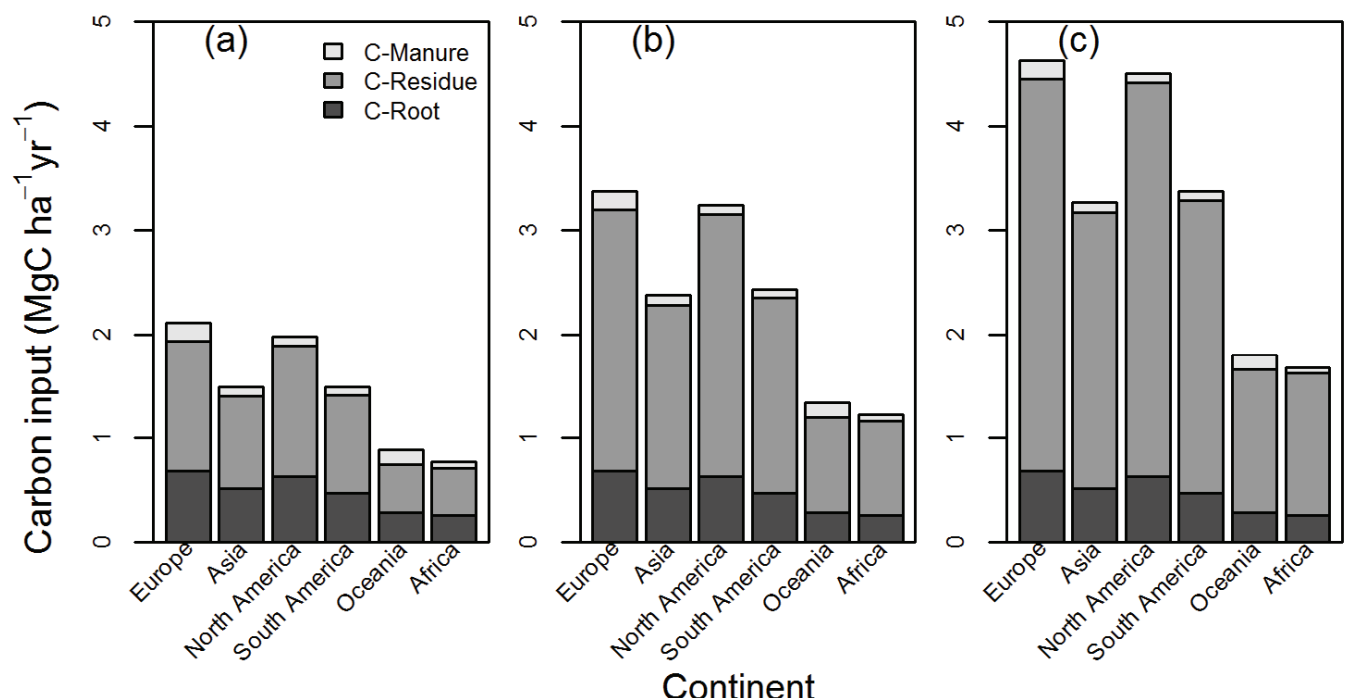

Figure S4. Carbon inputs across five continents in the global main cereal cropping regions under different above-ground crop residue retention rates of 30\% (a), 60\% (b) and 90\% (c). 